\title{
EL CANZONIERE DE BOSCÁN (LIBRO II, BARCELONA, 1543)
}

\author{
BIENVENIDO MORROS MESTRES \\ Universidad Autónoma de Barcelona
}

Para mi hija Ingrid

Si Boscán ha tenido alguna importancia, que sin duda la ha tenido, en la historia de la literatura en castellano, no ha sido tanto por haber introducido en ella las «trovas italianas», sino por haber integrado en un volumen de versos, repartido en cuatro libros, las diferentes tradiciones poéticas que podían cultivarse en España a mediados del siglo XVI. En el libro I de sus obras, Boscán ofrece a sus lectores una tradición que cree ya agotada, la de la poesía en octosilabo, que es la que conoce mejor y en la que se siente más cómodo. En el libro II, brinda un verdadero cancionero petrarquista, el primero de nuestra lengua: un cancionero que presenta cierta unidad y que plantea una clara evolución desde el amor enfermizo a otro más sano y sereno, inspirado sin duda por su mujer doña Ana Girón de Rebolledo. En el libro III, incluye una serie de composiciones teñidas por un incuestionable clasicismo: la fábula mitológica, la epístola tanto horaciana como ovidiana y la elegía amorosa, a la que da el nombre de capítulo. En el libro IV, al reservarlo para las obras de su amigo Garcilaso, no hace sino confirmar esa última tradición, al añadir nuevos géneros, como la oda horaciana y la égloga virgiliana.

De esos tres libros me interesa por ahora el segundo por ser el libro al que el poeta barcelonés dedicó más tiempo y que preparó en diversas etapas. Antonio Armisén, el crítico que mejor lo ha estudiado, ya se percató de la complejidad del libro II al examinar las diferencias entre el manuscrito LastanosaGayangos (que designa con la letra $L$ ) y la edición barcelonesa de Carles Amorós (conocida tradicionalmente por la sigla $O$ ). Voy a tomar como punto de partida sus consideraciones al respecto, que suscribo casi en su totalidad.

RFE, LXXXV, 2005, 2. ${ }^{\circ}$, págs. 245-270 


\section{EL MANUSCRITO Y LA EDICIÓN}

El manuscrito $L$ recoge en diversos apartados los poemas que, salvo alguna excepción, acabarán conformando el libro II de $O$ (Barcelona, 1543). Empieza por reproducir, en un primer grupo, siete canciones de Boscán, de las cuales la última no figurará en la edición, mientras que las otras seis están copiadas casi en el mismo orden que en ésta: son las canciones XLVII, LI, XLVIII, LIII, LXVI y LXXIV (reproduzco la numeración que los editores modernos han otorgado a esas mismas canciones en $O$ ). Como es fácil de comprobar, sólo una canción, la LII, está fuera de su lugar: debía ser la tercera, y no la segunda, de la serie, detrás de la XLVIII y antes de la LIII ${ }^{1}$.

En un segundo grupo, con idéntico epígrafe, $L$ transcribe otras tres canciones de Boscán en el mismo orden que en la edición: las canciones XCVII, CIII y CIV. Entre las seis de un grupo y las tres del otro obtenemos nueve de las diez canciones que aparecen en $O$ : el manuscrito transcribe una canción que suprime la edición y deja de reproducir otra (la $\mathrm{CXXX)}$ con que en el impreso se cierra el libro II. Si la incluye es porque Boscán aún no la había escrito cuando $L$ se copió. En ese sentido, el manuscrito refleja una primera etapa en la preparación de ese libro para la imprenta de Carles Amorós.

En otros dos grupos, también por separado, $L$ recoge muchos de los sonetos que luego figurarán en la princeps. En un primer grupo, reproduce cuarenta sonetos en un orden muy similar al de $O$ : sólo el XXXIX aparece situado antes del LIX, y es que ese soneto de haber estado en su sitio habría abierto en el manuscrito la serie de sonetos de Boscán. En el segundo grupo, incluye sólo seis, pero dispuestos de la misma manera que en la edición. Con respecto a ésta en el manuscrito faltan, por un lado, los diez primeros sonetos (del XXIX al XXXVIII) y el duodécimo (XL), y, por otro, los últimos veinticinco (del $\mathrm{CV}$ al $\mathrm{CXXIX}$ ). Tales ausencias no hacen sino confirmar que el manuscrito $L$ representa un estadio anterior a la edición, como ya había conjeturado Antonio Armisén:

No podemos asegurar que todos los sonetos ausentes del manuscrito fuesen escritos en la última época de la vida del barcelonés, pensando en completar una forma concreta que requería nuevos textos; pero ésta parece una posibilidad a considerar y explica la ausencia de las secciones inicial y final en el manuscrito. El cuidado puesto en ambas permite confirmar una intención formal consciente y muy definida ${ }^{2}$.

${ }^{1}$ Una descripción detallada del manuscrito ofrecen Antonio Armisén, Estudios sobre la lengua poética de Boscán. La edición de 1543, Zaragoza, Póntico, Universidad de Zaragoza, 1983, págs. 379-384; y Alberto Blecua, "Garcilaso con stemma», en Busquemos otros montes y otros ros. Estudios de literatura española del Siglo de Oro dedicados a Elías L Rivers, eds. Brian Dutton y Victoriano Roncero Lopez, Madrid, Castalia, 1992, pág. 25.

2 Op. cit., pág. 383. 
No hay duda de que Boscán pensaba «completar una forma concreta que requería nuevos textos». Pero ¿cuál era esa forma? La respuesta, en principio, no parece demasiado difícil: la de un libro de poesía articulado y pergeñado a semejanza de los Rerum vulgarium fragmenta de Petrarca, o al menos con el aspecto y disposición que le dieron los editores de principios del siglo XVI, no muy distinta a la voluntad del poeta plasmada en el manuscrito Vaticano Latino 3195. En ese modelo, como veremos en seguida, Boscán también tuvo en cuenta los poemas de Ausiàs March en el orden y presentación con que fueron impresos por el editor que iba a encargarse de las obras del barcelonés ${ }^{3}$. Ese editor no era otro que Carles Amorós, quien en 1543 no sólo publicaría los textos de su paisano, sino también los del poeta valenciano.

Si analizamos las ausencias que se producen en $L$ notaremos en seguida que por el principio faltan los primeros cuatro sonetos proemiales y que por el final no están los sonetos inspirados en uno de los poemas más célebres de March, ni los sonetos de tema neoplatónico, ni la canción última de contenido religioso. Parece obvio que Boscán redactó esos sonetos y la última canción en una fase posterior a la copia del manuscrito, y lo hizo pensando en Petrarca y en March.

\section{EL, ORDEN DE LOS POEMAS}

En la carta a la duquesa de Soma, el barcelonés alaba a los dos poetas casi por igual, y del valenciano lega a mencionar el interés que sus obras habian despertado en el Almirante de Nápoles don Fernando Folch de Cardona, a quien recuerda mandándolas copiar para poderlas llevar siempre consigo:

De estos proençales salieron muchos autores ecelentes catalanes, de los cuales el más ecelente es Osias March, en loor del cual, si yo agora me metiese un poco, no podría tan presto volver a lo que agora traigo entre las manos. Me basta para esto el testimonio del señor Almirante, que después que vio una de sus obras las hizo luego escribir con mucha diligencia y tiene el libro dellas por tan familiar como dicen que tenía Alexandre el de Homero ${ }^{4}$.

$\mathrm{Y}$ es que don Fernando jugó un papel crucial en la difusión de la obra de Ausiàs March en el siglo XVI, tanto manuscrita como impresa. Por lo que respecta al primer tipo de tradición, se han conservado dos manuscritos con los

${ }^{3}$ De ello ya se percataron parcialmente Lluís Cabré y Jaime Turró, «Perché alcun ordine gli habbia ad esser necessarion: la poesía 1 d'Ausiàs March i la tradició petrarquistan, Cultura neolatina, LV, 1995, especialmente págs. 132-134.

4 Para los textos de Boscán usamos la edición de Carlos Clavería, Obra completa, Madrid, Cátedra, 1999, págs. 119-120. Los números de las páginas después de una cita de sus versos remiten siempre a esta edición. 
poemas del valenciano encargados por el Almirante. Los dos fueron copiados, según consta en cada uno de los respectivos colofones, por Pere de Vilasaló: uno el 9 de mayo de 1541; el otro el 23 de abril de 1542. El primero pertenece a la Biblioteca Nacional de París (conocido con la sigla $B$ ), y el segundo se halla en la Biblioteca General de Cataluña (identificado con la sigla $K$ ). Don Fernando, además, patrocinó las dos primeras ediciones barcelonesas de la obra de March, las dos preparadas en la imprenta de Carles Amorós, una de 1543 y la otra de 1545: "per manament del Ille Almirant de Nàpols don Ferrando de Cardona», según aclara Luis Caroz de Vilaragut en el prólogo del manuscrito que copia Jeroni de Figueres el 1 de mayo de 1546. En la tercera edición publicada en la ciudad Condal, no en la misma imprenta que las anteriores, sino en la de Claudi Bornat, en 1560, el editor escribe un prólogo que dirige al Almirante y en el que afirma haber revisado el texto «a imitaçió de la vostra senyoria» 5 .

Todos esos testimonios de la poesía de March, con la excepción del manuscrito $K$, presentan una serie de peculiaridades frente a otras ediciones y manuscritos. La más importante de tales diferencias es el orden en que todos ellos disponen la obra del valenciano. Así, por ejemplo, esos testimonios sitúan encabezando la colección el poema que habitualmente aparece con el número XXXIX, el que empieza «Qui no és trist de mos disctats no cum ${ }^{6}$. La edición princeps de la obra marchiana (Valencia, 1539) había elegido como poema proemial el que en otros muchos testimonios abre el cancionero del valenciano, el que comienza "Així com cell qui·n lo somni es delita».

Así las cosas, Boscán no pudo escribir antes del 9 de mayo de 1541 el soneto que inaugura el libro II en la edición de Carles Amorós. Entre ese soneto y el poema de March que encabeza la colección en el manuscrito $B$ (y también en las ediciones barcelonesas) hay notables coincidencias que obligan a conjeturar que nuestro poeta si tuvo como modelo ese poema es porque éste figuraba al principio del resto de composiciones del valenciano: el lugar tan preeminente que ocupa el poema en $B$ (y en las ediciones mencionadas) es lo que llamó la atención de Boscán. De no ser así el barcelonés no lo habría escogido para imitarlo en el primer soneto de su libro II.

\footnotetext{
5 Toda esta información sobre los manuscritos y las ediciones de March está sacada de Robert Archer, ed., Obra completa, Barcelona, Barcanova, 1997, vol. II, págs. 11-23.

${ }^{6}$ De hecho, manuscritos con ese orden de los poemas fueron habituales, en el ambiente barcelonés, desde finales del siglo XV o principios del XVI, según los han documentado Lluís Cabré y Jaime Turro, art. cit., pág. 129. Sin embargo, para el círculo en que se mueve Boscán, el manuscrito de Vilasaló constituye un buen punto de referencia para fechar su obra.
} 


\section{LOS SONETOS PROEMIO}

Pero antes de continuar no estará de más precisar cuáles son esas coincidencias entre las dos composiciones. Boscán no parece sentirse orgulloso de la historia de amor que narra en sus versos, pero la ofrece a sus lectores para que eviten tales males; se dirige principalmente a aquellos que se complacen en la lectura de sus poemas como quienes se deleitan en las tristezas ajenas para aprender de ellas a mantenerse al margen del amor y a dar gracias a Dios por conseguirlo:

¡Oh vosotros, que andáis tras mis escritos, gustando de leer tormentos tristes, según que por amar son infinitos!, mis versos son deciros: «jOh benditos los que de Dios tan gran 'merced hubistes que del poder d'amor fuésedes quitos!» (121)

Ausiàs March, por su parte, predispone a los lectores a tener un determinado estado de ánimo para poder leer sus versos, que presenta exentos de cualquier artificio, al creerlos compuestos por alguien que ha perdido la razón:

Qui no és trist de mos dictats no cur,

$O$ en algun temps que sia trist estat;

E lo qui é de mals passionat,

Per fer-se trist, no cerque lloc escur;

Llija mos dits, mostrants pensa torbada,

Sens alguna art eixits d'hom fora seny?

Los copistas de la obra de March pudieron reconocer en estos versos afinidades con los que Petrarca elige para el soneto que inicia sus Rerum vulgarium fragmenta. Especialmente en el apóstrofe del poeta a los destinatarios de su obra, con la invitación a leer y a escuchar sus versos, dictados más por el corazón que por el entendimiento, y por eso sometidos a una variedad de registros estilísticos, que son reflejo de sus diferentes estados de ánimo:

Voi ch'ascoltate in rime sparse il suono

Di quei sospiri ond'io nudriva 'l core

In sul mio primo giovenile errore

Quand'era in parte altr'uom da quel ch'i'sono:

Del vario stile in ch'io piango et ragiono,

Fra le vane speranze e " 1 van dolore,

${ }^{7}$ Los poemas de Ausiàs March están citados por la edición Robert Archer, 1997, vol. I, pág. 170. 
Ove sia chi per prova intenda amore,

Spero trovar pietà, nonché perdono ${ }^{8}$.

No es éste el lugar para determinar qué poema, entre los de March, satisface mejor los requisitos de prólogo para su colección: si el que acabamos de analizar, o el poema con que otros testimonios deciden abrir las obras del poeta valenciano, aquel que empieza con los versos «Així com cell qui en lo somni·s delita/ e son delit de foll pensament ve», en los que Baltasar Romaní proyecta la sombra de Petrarca cuando los traduce por «Bien como aquel que'n sueños devanea/ y se deleita de vano pensamiento», con claras reminiscencias de «le vane speranze e 'I van dolore», pero sobre todo de «e del mio vaneggiar vergogna è ' 1 fruto» ${ }^{9}$. Nuestro objetivo por ahora es otro: demostrar hasta qué punto Boscán se basó en el orden en el que leyó la poesía completa de March, al margen de si ese orden estaba más o menos influido que otros por el Canzoniere de Petrarca.

En otro de los cuatro sonetos que desempeñan la misma función de prólogo, Boscán parece describir alegóricamente la situación en que ha visto peligrar su vida, al presentarse llevando en la mano el fuego que lo ha consumido y con las penas caminando por delante de su persona:

$$
\begin{aligned}
& \text { Delante van las penas que'n mi siento } \\
& \text { Dando nuevas de mi desasosiego, } \\
& \text { Y en las manos llevando el vivo fuego } \\
& \text { Do ardiendo 'stá mi triste pensamiento (123). }
\end{aligned}
$$

Para semejante representación ha podido inspirarse en una similar, y muy conocida en la época, de La cárcel de amor de Diego de San Pedro, en que el protagonista, Leriano, aparece arrastrado por un caballero salvaje, símbolo del deseo irracional, que lleva en su mano derecha el retrato de una dama del que salen rayos de fuego:

Por unos valles hondos y escuros que se hacen en la Sierra Morena, vi salir a mi encuentro [...] un caballero aś feroz de presencia como espantoso de vista, cubierto todo de cabello a manera de salvaje; llevaba en la mano izquierda un escudo de acero muy fuerte, $y$ en la derecha una imagen femenil entallada en una piedra muy clara, la cual era de tan estrema hermosura, que me turbaba la vista; salían della diversos rayos de fuego que llevaba encendido el cuerpo de un hombre que el caballero forciblemente llevaba tras $s 1^{10}$.

\footnotetext{
${ }^{8}$ Marco Santagata, ed., Petrarca, Canzoniere, Milán, Mondadori, 1996, pág. 5; para los modelos del soneto prólogo de Petrarca, véase Francisco Rico, «Prólogos al Canzoniere (Rerum vulgarium fragmenta, I-III)", en Estudios de literatura y otras cosas, Barcelona, Destino, 2002, págs. 111-146.

9 Véase al respecto Lluís Cabré, «Algunes imitacions i traduccions d'Ausiàs March al segle XVl», Quaderns. Revista de traduccí, VI, 2002, págs. 70-71.

10 Diego de San Pedro, Cácel de amor, ed. Carmen Parrilla, con estudio preliminar de Alan Deyermond, Barcelona, Crítica, 1995, pág. 16.
} 
A partir de este pasaje del inicio de La cárcel de amor Boscán ha escogido la imagen del salvaje para expresar la clase de deseo que ha inspirado el amor de una etapa importante de su vida, la de la juventud, antes de alcanzar la madurez casándose con Ana Girón de Rebolledo, no mucho después de haber cumplido los cuarenta años. Al pensar en un personaje como Leriano, que acaba suicidándose, prevé para quienes se obstinen en ese tipo de amor el mismo final y, por tanto, el abandono de sus cuerpos en pleno campo, en lugar de una sepultura cristiana («Dinos serán de ser al campo echados»).

\section{LOS SONETOS CON SIMLES}

En el manuscrito $B$, el poema inicial (el XXXIX en otros testimonios) está seguido por el que en otras colecciones es el que abre el cancionero, el ya citado «Així com cell qui en lo somni-s delita». Este poema, en las ediciones de Carles Amoros, no aparece situado tras el XXXIX, sino en un lugar mucho más retrasado, treinta y dos poemas después que el primero, entre las esparzas LXXXX y LXXXI, que son de mera transición; en la edición de Claudi Bornat, al relegarse las esparzas a un apartado específico para ellas, el poema en cuestión ocupa un sitio entre el LIV y el LXII. El dato es importante porque Boscán escoge ese poema de March para imitarlo en una serie de sonetos que introduce después de las canciones CIII y CIV y que marcan un claro punto de inflexión en su cancionero. Se trata de los sonetos CV, CVI, CVII, CVIII, CIX, CX, CXI y CXII, precisamente los primeros que faltan por el final en el manuscrito Lastanosa-Gayangos ${ }^{11}$. Para facilitar una rápida comparación entre las dos ediciones barcelonesas, reproducimos a continuación el orden de los poemas en cada una de ellas (las dos ediciones de Amorós reciben las siglas $b$ y $c$, mientras la de Bornat tiene la sigla $e)^{12}$ :

$b$ y $c$ [Obres de amor] XXXIX, IV, LXVI, CI, III, XXI, LXIX, LXVII, X, LXVIII, XXIII, XXXVII, CIX, XXXIII, V, XXXIV, LXXIII, XIIV, LXXXVI, L, XVIII, LI, XXIV, LXXXIX, XIII, II, XIXX, VII, LIV, LXXX, I, LXXXI, LXXXII, LXII, XI, XIV, XI, XXXII, XVI, XXXI, XX, XXVI, XXXVI, LV, XLI, C, LVII, XXVII, XLV, XXII, XIVI, IX, LXXXV, XXXVIII, CXIV, XXVII, XC, LIII, XCI... [Obres de mort] CXXIII, XCII,

${ }^{11}$ Esas deudas con el poena de March ya fueron señaladas por Marcelino Menéndez Pelayo, Antologia de poetas líricos castellanos, Santander, CSIC, 1945, pags. 260-264. De esos sonetos el CX también está inspirado por el mismo poema de March, por la estrofa en que el valenciano expresa el deseo de no mezclar el dolor con el placer («Fora millor ma dolor sofréri que no mesclar poca part de plaers; 38): en este caso, Boscán prescinde del símil del enfermo que por un día abandona la dieta que le ha prescrito el médico.

12 El orden de los poemas de March tanto en manuscritos como en ediciones aparece reproducjdo por Robert Archer, ed. cit., vol. II, págs. 36-37. 
XCIII, XCIV, XCV, XCVII, XCVI [Obres morals] CIII, CIV, CVI, CIII, CVII, CXII, CVIII, CV.

$e$ [Cants de amor] XXXIX, IV, LXVI, CI, III, XXI, LXIX, LXVI, X, LXVIII, XXIII, XXXVII, CIX, XXXIII, V, XXXIV, LXXIII, XLIV, LXXXVI, L, XVIII, LI, XXIV, LXXXIIX, XIII, II, XIX, VI, LIV, I, LXII, XI, XIV, XL, XXXII, XVII, XXXI, XX, XXVI, XXXVI, LV, XLI, C, LVIII, XXVII, XIV, XXII, XIVI, LX, LXXXV, XXXVIII, CXIV, XXVIII, XC, LIII, XCI...[Coplas esparças] LXXXVI, LXXX, LXXXI, LXXXIII, LXXXII, CII [Demandas y respostas] CXXV, CXXVI [Obras morals] LXXII, XXIX-XXX, XXXII, XXXI, XXVI, XLI, LVII, CXXI, CIII, CIV, CVI, CXIII, C, CVIII [Cant spiritual] CVI [Obras de mort] XCI, CVII, $\mathrm{XCIII}, \mathrm{XCIV}, \mathrm{XCV}, \mathrm{XCVII}, \mathrm{XCVI}, \mathrm{CXII}$.

En las tres ediciones, la configuración del cancionero amoroso de March es muy similar: en la edición de 1560 se produce el desplazamiento ya señalado de las esparzas, pero también se cierran las obras de amor con el poema CXXIII, mientras que en las ediciones de Amorós se hace con el LXXXVII. Bornat, por su parte, introduce en la suya más secciones, las «Coplas esparzas» y «Demandas y respostas», y intercambia el orden de las «Obras morals» y «de mort», en las que no incluye siempre los mismos poemas que su colega y paisano.

Nos vamos a ceñir por el momento al análisis de las «Obres de amor» de March para seguir poniéndolas en relación con las de Boscán. El barcelonés, como hemos visto, ha decidido situar nueve sonetos inspirados en prácticamente un poema del valenciano a una altura bastante significativa de su cancionero, porque todos ellos suponen una transición hacia una segunda parte muy marcada. Digo que son sonetos prácticamente inspirados en un poema de March, porque hay uno que está influido por otro de su modelo, y un segundo, el último de la serie, que carece de una fuente específica. Esos nueve sonetos, salvo las excepciones subrayadas, son una clara imitación del poema I de March, que en las ediciones de Amorós y Bornat aparece también a una altura bastante importante de las «Obres de amor», pero que no marca una transición tan clara hacia el planteamiento de temas distintos.

\section{EL NUEVO AMOR}

Después de todos esos sonetos Boscán introduce otro, el CXIV, en el que ya abiertamente se presenta libre de la prisión amorosa, y en el que, al recibir un primer golpe por parte de Cupido, al verlo con otras armas diferentes a las acostumbradas, no espera el segundo y emprende la huida para librarse de una cárcel de la que antes no había podido salir. En ese soneto el poeta barcelonés parece haber abandonado el sufrimiento por un sentimiento nuevo, ratificado 
en los sonetos posteriores, en los que canta un nuevo amor, mucho más sereno y sosegado, un amor que define como de salud porque es correspondido («pues amo blandamente y soy amado", reconoce en el soneto CXV). En el cancionero de March, si prescindimos de las esparzas, después del poema I, tenemos el LXII, en que el poeta se siente el hombre más feliz del mundo porque se imagina amado por su dama, en la creencia de que «Dos cors units en una voluntat/ deu fer amor» (vv. 29-30), aunque al final sospecha, y es ése el miedo que tiene, que ella no lo ame con la misma intensidad con que to hace él.

En la segunda parte de su cancionero, más breve que la primera, Boscán recrea motivos tomados del neoplatonismo, a la vez que plantea cuestiones inspiradas, aunque no tan claramente como en los nueve sonetos anteriores (del CV al CXII), por otros poemas de March, situados también ya en la parte final de sus «obres de amon», después, por supuesto, del poema I. Así, por ejemplo, en el soneto CXIV, el poeta barcelonés reconoce estar iniciando «un nuevo canto» dictado por otro tipo de Amor muy diferente al que antes lo había hecho llorar; define ese nuevo amor como "provechoso», que es el resultado de una mezcla muy especial propiciada por la razón:

Razón juntó l'honesto y deleitable,

$\mathrm{Y}$ de 'stos dos nació lo provechoso,

Mostrando bien de do engendrado fue (226)

En sus Diálogos de amor, como ya advirtió A. Armisén, León Hebreo define el amor marital como una suma de los tres amores que ha distinguido un poco antes, una conjunción entre el honesto, el deleitable y el útil. Para Hebreo el amor deleitable, como el coito, antes de adquirirse, se desea y ama, pero, una vez adquirido, ni se desea ni se ama; en el amor por interés ocurre lo contrario: lo útil, como la riqueza, antes de poseerse, se desea pero no se ama, pero, ya poseída, deja de desearse para sólo amarse; lo honesto, como la sabiduría o la virtud, se desea y ama cuando no se tiene, y, cuando ya se ha conseguido, se sigue amando, pero no deseando. El amor por deleite entre los casados es efímero, porque, una vez consumado, deja de anhelarse; por eso, debe unirse con el amor honesto (o espiritual), que es un tipo de amor en que se sigue amando después de alcanzado, porque el amor matrimonial basado únicamente en el deleite se extinguiría en seguida. Para garantizar la supervivencia del amor entre los casados, también debe darse el amor por interés, porque de esa manera los consortes se benefician mutuamente de su relacion:

Manifiesto es ser deleite el amor de los casados, empero debe ser conjunto con el honesto; y por esta causa, después de que es habida la delectación, queda siempre conservado el recíproco amor, y por la naturaleza de las cosas honestas crece continuamente. Júntase también con el amor matrimonial el 
útil con lo deleitable y el honesto, porque de contino reciben los casados utilidad el uno del otro, lo cual es gran causa de que se siga y conserve el amor entre ellos. Así que, siendo el amor matrimonial deleitable, se continúa por la compañía que tiene con el honesto y con el útil y con ambos a dos juntamente (p. 62)

En el soneto cuyo primer terceto hemos reproducido arriba, Boscán alude claramente al amor por su esposa Ana Girón de Rebolledo, al presentarlo como una unión entre lo honesto y deleitable, que es la que garantiza su pervivencia. Sin embargo, y en eso consiste su originalidad, reconoce que de esa unión nace un tercer tipo de amor, el útil o "provechoso», pensando, no tanto en los beneficios económicos de su matrimonio, que los tuvo, sino en el tipo de amor que persiste una vez se ha alcanzado y que practicado con templanza produce «conformidad o satisfacción de lo necesario», como acalara el propio León Hebreo.

En el poema LXXXVII, con el que Amorós clausura el cancionero amoroso, March empieza también distinguiendo esos tres tipos de amor, que toma, al igual que hará León Hebreo, de las tres clases de amistad que Aristóteles había señalado en el De anima; rechaza el amor por provecho y se decanta por el que une lo deleitable con lo honesto generando un tipo de amor que llama «mesclat voler»:

Tres amors són per on amadors amen;

L'u és honest, e l'altre delitable;

Del terç me call, que és lo profit amable

Per què-ls amats llurs amants no reamen.

Los dos units en nós se poden pendre,

Si llurs dos focs han lloc en nós d'encendre (337)

En el poema CXXIII, que en la edición de Bornat cierra las «obras de amor», el poeta valenciano insiste de nuevo en la idea de un amor como resultado de la conjunción de varios tipos de amor, especialmente el deleitable y el honesto, a los cuales ahora añade el «mesclat voler»:

Sí com lo cos bé format se pot dir

Quan egualment los membres ha formats,

Tal és amor quan ses tres qualitats

En actes tres hom veu aquell eixir;

Car hom veu clar l'apetit corporal

E del compost, d'on pren forma l'honest,

Dels quals és l'hom, si bé ama, conquest.

Sens tots aquests eguals, amor poc val (647-648)

Un poco más abajo, compara el amor humano, mezcla de todos esos tipos de amor, con el amor por interés, al creer que el amante, en ambos casos, no 
es capaz de distinguir entre los dos componentes de su amor, el físico y el espiritual o el egoísta y el altruista:
Així com és l'amant per interés
A son amic, del qual gran bé li ve:
Ell ama aquell e més son propi bé,
No veu son foc per dos part ser encès,
Així són dos esguards d'aquesta amor
$E$ no es veu bé que sia sino ú (649-650).

La ecuación que plantea Boscán (amor honesto más amor deleitable igual a amor útil) también podía entenderse desde esa perspectiva: los dos tipos de amor engendran un tercero, el «mezclar voler», que guarda similitudes con el amor por interés. De hecho, el poeta barcelonés, en sus últimos sonetos, no reivindica un amor cien por cien platónico, sino un amor en que se dan las condiciones del «mezclat voler» anhelado por March. La única diferencia es que para nuestro poeta no parece demasiado difícil de asumir, sobre todo porque lo acomete dentro de su matrimonio con Ana.

Entre los «cantos de muerte», escritos con ocasión de la de su segunda mujer Joana Escoma, en el poema XCIII, Ausiàs March se plantea qué amores, de los que había distinguido en poemas anteriores, han sobrevivido a la muerte de la amada para llegar a la conclusión de que dos han perecido con ella, el útil y deleitable, y de que el tercero, el honesto, ha podido sobrevivir gracias a la ayuda divina. En el fondo deja traslucir que en su vida marital habían coexistido esos tres tipos de amor, que designa con el nombre de «bienes» y a los que ha comparado con tres pájaros a los que un arquero ha cazado de un solo disparo, dando muerte a dos y dejando muy malherido al tercero:

Arquer no sé que tres ocells plagas

$\mathrm{Ab}$ un sol colp, que no fos ben content,

Matant los dos, i el terç en estament

Que per mig mort o prop de mort portàs.

Mort en un colp los tres béns m'ha ferits;

Los dos són morts: l'útil e.l delitos;

E si l'honest perdés del cel recors,

Sos derrers jorns serien ja finits (388-389)

En el soneto CXVIII, Boscán canta ese «nuevo amor» que le ha inspirado su mujer en contraste con el amor del pasado, que, como si fuera la peste, llegó a matar en pleno vuelo a los pájaros:

Anduvo sobre mí gran pestilencia

Hasta matar los pájaros volando

$Y$ casi cuanto en vida fue criado (229) 
¿De qué pájaros se trata? Seguramente de los pájaros que en March simbolizan esos tres tipos de amor que la muerte se ha llevado. En nuestro poeta, es el amor más enfermizo el responsable de la defunción de las tres clases de amor que han resucitado tras la boda con Ana Girón de Rebolledo. El amor del pasado no había sido honesto, pero tampoco útil ni deleitable, porque el poeta no había sacado de él ningún beneficio ni placer. Más bien todo lo contrario.

En un sermón sobre el matrimonio, predicado en 1427 en su ciudad natal, san Bernadino de Siena exhorta a todos, hombres y mujeres, a buscar el amor dentro de ese santo sacramento porque en él se conjugan tres tipos de bienes, correspondientes a los tres tipos de amor, que engendran la verdadera amistad entre los cónyuges:

E però dico a tuttí voi uomini, e a tutte voi donne, seguitate le virtù, acciò che l'amore abbi queste tres cose: utile, dilettevole e honesto; e serà infra voi vera amicizia. E quando tu avrai queste tre cose, ode David che dice de te: «Uxor tua sicut vitis abundans in lateribus domus tue». Doh! Tutte tre queste cose ci sono dentro. Prima v'è l'onesto: «Uxor tua», la tua donna. Sicondo, dilettevole: «sicut vitis»; quanto è dilletevole cosa une vite dinanzi a un uscio! Terzo, è utile, «abundans», abondante, che fa dell'uva, ciò fruttuosa. Delle quali tre cose vien a nasciare e perseverare la vera amizia infra donna e l'uomo, i quali so' congionti col sagramento del santo matrimonio ${ }^{13}$.

('Y sin embargo digo a todos vosotros hombres y a todas vosotras mujeres, seguid la virtud, para que el amor sea estas tres cosas: útil, deleitable y honesto; y habrá entre vosotros verdadera amistad. Y cuando tengáis estas tres cosas, oíd a David que dice de ti: «Tu mujer abundante como la vid en las puertas de tu casa'. ¡Oh! Todas estas tres cosas están dentro. Primero es lo honesto: «Tu mujen». Segundo, deleitable: «como la vid» ¡Cuán deleitable es la vid ante una puerta! Tercero es útil, abundante, que produce la uva, fructúfera. De las tres cosas viene a nacer y perseverar la verdadera amistad entre marido y mujer, las cuales están unidas en el sacramento del santo matrimonio').

Al igual que March, Boscán halla dentro del matrimonio un amor mixto o compuesto, pero para nuestro poeta no genera ningún tipo de tormento o sufrimiento, mientras que para el valenciano sí se lo produce. En ese sentido, el barcelonés ofrece un planteamiento muy próximo al de un paisano suyo, Romeu Llull, quien también se casa una vez ha cumplido los cuarenta años. En una de sus pocas obras en prosa, la titulada Lo despropriament d'amor, utilizando la forma alegórica, al igual que Petrarca en su primer triunfo, el de

${ }^{13}$ El texto lo aporta Lola Badia, Tradició i modemitat als segles XIV $i \mathrm{XV}$. Estudis de cultura literdria i lectures d'Ausiàs March, Publicaciones de l'Abadia de Montserrat, Valencia- Barcelona, 1993, págs. 152-153, n. 15. 
amor, narra su historia sentimental. Primero, acompañado por una dama que es la Esperanza, ingresa en la orden de Cupido, cuando sólo tiene dieciséis años, pero, tras llevar veinticuatro vistiendo los hábitos de Ingratitud, al servicio de una dama llamada Serena, por quien nunca es correspondido, decide abandonar la orden para acogerse a otra más santa y segura, la del matrimonio con su prima Joana Llull i Llull:

Agut complit fi lo meu despropriament, trobant-me libert e fora lo coll de aquell penós e penat jou de fol amor, aconsellat per la sana rahó [...] E axí, entrant en la sancta religió del matrimoni, pres aquell honrat e gloriós ábit de virtuosa amor, acompanyat de companyia tal que un sí e un no units nos té, e segons per Déu és dit, «Et erunt duo in carne una», tot altre fol pensament a part lansat, de honests desigs, honrats delits, grats plers, e de temprats anuigs no freturós, lo restant de ma vida ab proposit ferm en aquest virtuós stament longament plasent a Déu desig viure ${ }^{14}$.

Ese «despropriament» Romeu Llull lo solicita y consigue en el templo de Cupido, donde muchos años antes había ingresado para formar parte de su orden o religión de amor. Por su parte Boscán, como explica en el soneto CXXVI, después de haber recuperado su libertad, decide colgar en el templo de Cupido los hierros que simbolizan su antigua esclavitud por amor, de la misma manera que los náufragos, tras haber escapado de una tormenta, solían colgar en el templo de Neptuno, en agradecimiento por haberlos salvado, sus ropas mojadas y los restos de la embarcación:

Sé que's así, no sé cómo se ha hecho

Que ahora, libre, entre todos me contemplo

De la fuerte prisión donde fui envuelto.

$\mathrm{X}$ así agora, en memoria d'un tal hecho, Colgando 'stoy los hierros en el templo,

Adonde amanecí despierto y suelto (vv. 9-14)

El tema no es nuevo, pues ya lo había planteado Horacio en sus Odas, a quien imita bastante de cerca Garcilaso en uno de sus sonetos, en concreto el VII. Sin embargo, Boscán no ofrenda sus ropas mojadas, sino los hierros y cadenas que atestiguan la prisión en la que ha vivido durante muchos años, $y$, además, ha conseguido su libertad en el templo de Cupido, al igual que el protagonista de Lo despropriament de Llull, quien se despoja de sus ataduras, en forma de diferentes ropas, en el mismo lugar en que se las había puesto.

\footnotetext{
14 Cito por la magnífica edición de Jaime Turró, Romeo Llull, Obra completa, Barcelona, Barcino, 1996, pág. 218.
} 


\section{LOS FUEGOS DE AMOR}

En los sonetos CXXI y CXXII, Boscán introduce una distinción entre dos tipos de fuego, uno el elemental, que lo ha consumido en el pasado, y otro cósmico, que lo vivifica e ilumina en el presente. Comienza recordando el primer tipo de fuego, tras exhortar a la búsqueda de un término medio en el amor, alejado de sus extremos:

Amor es bueno en sí naturalmente,

Y por causa d'él males tenemos,

Será porque seguimos los estremos,

$\mathrm{Y}$ así es culpa de quien sus penas siente.

El fuego es el más noble y ecelente

Elemento de cuantos entendemos,

Mas tanta leña en él echar podremos,

Que al mundo abrasará su fuerza ardiente.

Cuanto más, si le echáis otras misturas

De pez o d'alquitrán para movelle,

Como aquellas que eché en mis desventuras;

Por donde el ardor de sus tristuras,

Tan quemado quedé, con encendelle,

Qu'n mi rostro se muestran mis locuras (231).

En este soneto se ha limitado a describir las propiedades del fuego elemental para presentarse como víctima de él. En el Filebo, por ejemplo, Platón reconocía la existencia de dos fuegos, uno en nosotros y otro en el universo: "Velut ignis est quidem apud nos et etiam in universo» (fol. $31 \mathrm{~b}$ ), y en esa tradición Giovanni Pico della Mirándola, en el Heptaplus, llegaba a señalar hasta tres tipos distintos, iguales a los mundos que había distinguido antes:

Est apud nos calor qualitas elementaris, est in caelestibus virtus excalfactoria, est in angelicis mentibus idea caloris. Dicam aliquid expressius: est apud nos ignis quod est elementum; Sol ignis in caelo est; est in regione ultramundana ignis seraphicus intellectus. Sed vide quid differant. Elementaris urit, caelestis vivificat, supercaelestis amat ${ }^{15}$

('El calor es en nosotros una cualidad elemental; en los cielos, una potencia calorífica, y en las mentes angélicas, una idea de calor. Lo diré de una manera más precisa: el fuego es en nosotros un elemento; en el cielo, el fuego es

15 Véase Eugenio Garin, ed., Giovanni Pico della Mirandola, «De hominis dignitate», «Heptaplus», «De ente et uno» e scritti vari, Florencia, 1942, pág. 188. Para la distinción entre esas tres clases de fuego en Lope de Vega, véase Dámaso Alonso, Poesía española. Ensayo de métodos y limites estilisticos, Madrid, Gredos, 1966, págs. 455-461; y Francisco Rico, El pequeño mundo del hombre. Forruna de una idea en la cultura española, Barcelona, Destino, 2005, págs. 220-223. 
el sol; en la región ultramundana, el fuego seráfico es el intelecto. Pero ved en qué difieren: el elemental quema, el celeste vivifica, el supraceleste ama').

En el Cortesano, Castiglione también parece considerar tres tipos de fuegos al describir el proceso de desmaterialización en el amor platónico ${ }^{16}$. Así, el amante se enciende al contemplar la belleza de una mujer, pero, abrasado por un fuego más perfecto, gracias a la imaginación, trasciende esa belleza particular para abarcar la universal, y, ya ardiendo en un fuego santo, con la ayuda del entendimiento, alcanza la idea de la belleza divina. Boscán conocía muy bien esa obra, porque la había traducido al castellano en 1534 , y, en esa labor, es bastante fiel al original, como podremos comprobar a continuación al reproducir en las dos lenguas los pasajes en que el embajador del Papa trata de todos esos fuegos:

Però quando qualche gracioso aspetto di bella donna lor s'appresenta..., subito che s'accorge che gli occhi suoi rapiscano quella imagine... ed [che] poco a poco la riscalda, e che quei vivi spirti che scintillan for per gli occhi tuttavia aggiungon nova esca al foco deve in questo principio provedere di presto rimedio, risvegliar la ragione e di quella armar la ròcca del cor suo; e talmente chiuder $\mathbf{i}$ passi al senso ed agi appetiti, che né per forza né per inganno entrar vi possano. Così, se la fiamma s'estinge, estinguesi ancor il pericolo... 17

Por eso, cuando viere a alguna mujer hermosa..., luego a la hora que cayere en la cuenta y viere que sus ojos arrebatan aquella figura... [y que] poco a poco la enciende [el alma del amante], y que aquellos vivos espíritus que en ella centellean de fuera por los ojos no cesan de echar a cada punto nuevo mantenimiento al fuego, debe luego proveer en ello con presto remedio, despertando la razón y fortaleciendo con ella la fortaleza del alma y atajando de tal manera los pasos a la sensualidad y cerrando así las puertas a los deseos que ni por fuerza ni por engaño puedan meterse dentro; y así entonces, si la llama del fuego cesa, cesará también el peligro [....]

E così non più la belleza particular d'una donna, ma quella universale, che tutti i corpi adorna, contemplarà; onde offuscato da questo maggior lume, non curerà il minore, ed ardendo in più eccellente fiamma, poco estimarà che prima avea tanto apprezzato

Y así no ya la hermosura particular de una mujer, sino aquella universal que todos los cuerpos atavía y ennoblece contemplará; y desta manera, embebecido y como encandilado con esta mayor luz, no curará de la menor y, ardien-

\footnotetext{
${ }^{16}$ La relación de esos sonetos con el libro IV de la obra de Castiglione ya había sido sugerida por Antonio Amnisén, op, cit., pág, 402, n. 188.

17 Para la versión original, utilizo la edición de Ettore Bonora, Il libro del contegiano, Milán, Mursia, 1984, págs. 339-347; para la traducción castellana de Boscán, cito la edición de Mario Pozzi, El cortesano, Madrid, Cátedra, 1994, págs. 521-531.
} 
do en este más ecelente fuego, preciará poco lo que primero había tanto preciado [...]

Però l'anima, aliena dai vicii..., rivolgendosi alla contemplación della propria sustancia..., apre quegli occhi che tutti hanno e pochi adoprano, e vede in se stessa un raggio di quel lume che è vera imagine della belleza angelica... $\mathrm{e}$ rapita dal splendor di quella luce comincia ad infiammarsi..., parendole aver trovato l'horma di Dio, nella contemplación del quale, come nel suo beato fine, cerca di riposarsi; e però, ardendo in questa felicisima fiamma, si leva alla sua più nobil parte, che è l'intelletto...

Por eso el alma apartada de vicios..., volviéndose a la contemplación de su propria sustancia... abre aquellos ojos que todos tenemos y pocos los usamos, y ve en sí misma un rayo de aquella luz que es la verdadera imagen de la hermosura angélica..., y así arrebatada con el resplandor de aquella juz, comienza a encenderse..., pareciéndole que allí ha hallado el rastro y las verdaderas pisadas de Dios, en la contemplación del cual, anda por reposarse; y así ardiendo en esta más que bienaventurada llama, se levanta a la su más noble parte que es el entendimiento...

Al final, al definir esa clase de amor, Castiglione no puede menos que comparar el último fuego con el material o elemental para atribuirle propiedades purgativas y depuradoras:

Tanto adunque è maggiore e più felice questo amor degli altri, quanto la causa che lo move è più eccellente; e prò, come il foco materiale afina l'oro, così questo foco santisimo nelle anime distrugge e consuma ciò che v'è di mortale e vivifica e fa bella quella parte celeste, che in esse prima era dal senso mortificata e sepulta (347)

Así que tanto es mayor y más bienaventurado este amor que los otros, cuando la causa que le mueve es más ecelente; y por eso, como el fuego material apura el oro, así este santísimo fuego destruye en las almas y consume lo que en ellas es mortal y vivifica y hace hermosa aquella parte celestial que en ellas por la sensualidad primero estaba muerta y enterrada (531)

En el soneto CXXII, Boscán parece aludir al segundo tipo de fuego, aunque podría compendiar en ése los otros dos fuegos que suele diferenciar la tradición neoplatónica, y así nuestro poeta tambiến podría estar pensando en los dos fuegos que Ausiàs March, en el poema LXXXVII, relaciona con el amor deleitable y con el amor honesto, uno físico y otro espiritual ( «Los dos units en nós se poden pendre, / Si llurs dos focs han lloc en nós d'encendre»):

Este fuego que agora yo en mí siento

Es puro y simple, y puesto allá en su 'spera;

Y cuando acá deciende su hoguera

Es porque tal materia le presento, 
Que'n su calor revivo y me caliento, Templando todo ' 1 aire en tal manera, Que, doquiera que 'stoy, es primavera, Con flores y con fruto en un momento.

Su luz, alderredor do 'stoy presente, Alumbra en un instante cuanto veo, Mudándolo en color claro y luciente. Si este tal fuego hurtara Prometeo, Cuando quiso alegrar la mortal gente, Tuviera gran desculpa su deseo (231-232).

Al cerrar el soneto como lo cierra, con la referencia al fuego que Prometeo robó a los dioses para entregárselo a los humanos, Boscán sí podía estar introduciendo una referencia al Cortesano, pero no a ninguno de los pasajes citados, sino a otro de comienzos del libro IV, en que Castiglione aduce el mito para ilustrar las carencias de los mortales:

Onde Prometeo rubò quella artificiosa sapiencia da Minerva e da Vulcano e da Vulcano, per la quale gli omini trovavano il vivere; ma no aveano però la sapiencia civile di congregarsi insieme nelle cittă e saper vivere moralmente, per esser questa nella ròcca di Iove guardata da custodi sagacissimi, i quali tanto spaventavano Prometeo, che non osava loro accostarsi... (293)

('Y así, en enmienda desto, Prometeo robo aquel artificioso saber de Minerva y de Vulcano, con el cual los hombres ganaban la vida, mas no alcanzaban aquel otro saber que era necesario para que supiesen estar juntos en las ciudades y hacer repúblicas y vivir moralmente, porque éste estaba dentro en aquella fortaleza de Júpiter, puesto a recaudo con grandes guardas, las cuales tanto espantaban a Prometeo, que no osaba llegarse a ellas... [459]')

En el Protágoras, para ilustrar cómo ciertas virtudes no se aprenden sino que son connaturales, Platón recurre al mito de Epimeteo y Prometeo, a quienes los dioses mandaron que modelasen a los seres vivos del barro de la tierra. Porque así se lo pidió a su hermano, Epimeteo se encargó de mezclar todos los elementos para crearlos, y se preocupó tanto por las especies animales que descuidó la humana, a la que dejó muy desprotegida. En ese punto intervino Prometeo robando la sabiduría a Minerva y el fuego a Vulcano para entregarles una y otro a los humanos; sin embargo, se olvidó de proporcionarles la 'sabiduría civil' por estar guardada en la fortaleza inexpugnable de Júpiter, en la que no se atrevió a entrar:

Deerat adhuc civilis hominibus sapientia. Erat illa quidem apud Iovem, cuius arcem ascendere Prometeo nondum licebat. Horribiles enim Iovis custodes circunstantes arcem Prometheum deterrebat. Ceterum communem Vulcani Minervaeque officinam, in qua artes excolebantur clam ingressus furatus est igneam Vulcani artem aliamque Minervae, atque homini tradidit qua vivendi 
facultas obtigit. Prometheus autem ut fert propter Epimetheum furti penas dedit $^{18}$.

('Faltaba a los humanos la sabiduría civil. Ésta estaba sin duda junto a Júpiter, a cuya fortaleza a Prometeo no se le permitía subir. Sin duda horribles guardas que cercan la fortaleza disuaden a Prometeo. A escondidas Prometeo entró en la oficina común de Vulcano y Minerva en que se pulían las artes, y robó el arte ígneo de Vulcano y el otro de Minerva, y se lo entregó al hombre para que obtuviera la facultad de vivir. Prometeo sin embargo, como le ocurrió a causa de Epimeteo, fue acusado de robo')

Al compararlo con el fuego que ahora lo vivifica y alumbra, Boscán sin duda cree que el de Prometeo era material o estaba incompleto (ésa es la gran diferencia con respecto al suyo), y para ello había de tener en mente la versión que de la fábula ofrecen Platón y Castiglione, en la que el fuego robado a Vulcano no satisface todas las necesidades de los seres humanos. En la tradición medieval, en cambio, ese fuego simboliza la vida y la sabiduría, como, por ejemplo, deja muy claro Alonso de Madrigal en su Comento de Eusebio:

furtó el fuego et traxolo a la tienra e allegolo a los pechos del hombre que había hecho de barro e diole vida. Por esto se entiende que el hombre levantado en alta especulación alcanza el conocimiento de las verdades. Et entonces furta el fuego del cielo [...] et entonces el hombre de barro se faze vivo porque alcanza el saber por el qual paresce ser hombre lo qual primero no parescía ${ }^{19}$.

\section{LA ENFERMEDAD DEL ALMA}

En esa segunda parte, en que exalta su amor por Ana Girón, el poeta de Barcelona evoca el que sintió por otras mujeres, y para explicar la falta de libertad en que entonces vivía recurre a la metáfora de su alma enferma de «perlesías ('parálisis'):

D'una mortal y triste perlesía

En su cama tendida mi alma' staba,

Y como el mal los nervios l'ocupaba,

Ni de pies ni de manos se valía.

El casto Amor, que Dios del cielo envía,

Le dijo en ver pena que pasaba:

«Suelta tus pies, tus manos te destraba,

toma tu lecho a cuestas y haz tu vía!».

\footnotetext{
18 Platón, Opera, versión latina por Marsilio Ficino, Venecia, 1491, fol. 82.

19 Véase Rosa López Torrijos, La mitología en la pintura española del Siglo de Oro, Madrid, Cátedra, 199S, pág. 246.
} 
Volví luego a mirarme y vime sano, Y caminé sin rastro de dolencia Por las cuestas así como en lo llano. ¡Oh poder eternal y soberano! ¿Quién sanará con propia diligencia si la salud no da tu larga mano? (235)

Para esa imagen de su alma, Boscán se ha inspirado en otra muy similar que March introduce en el poema LXXIV para quejarse de que no puede hacer lo que quiere. En ese poema, situado también en el último tramo de su cancionero amoroso, el poeta valenciano comienza presentando su voluntad como enferma (ésa es en la tradición agustiniana una de las tres partes del alma), y en la segunda estrofa precisa la naturaleza de semejante enfermedad, al compararla con la de un hombre que está paralítico y que no puede dirigirse al lugar al que desea encaminarse:

Ja no és temps tenir frens al voler; Malalta és ma bona voluntad, E vaig en lloc on no vull ser portar; S6 descontent de tot quant pusca fer. Sí com a l'hom no li basta poder, Paralític, quan és en peus llevat, Anar al lloc on vol ésser anat, Ans cau o tort va contra son mester, Ne pren a mi, que faç lo que no.m plau, I aquell voler de la rá és vençut (298-299)

Si en Boscán es el alma entera la enferma, en March sólo lo es una de sus partes, pero en los dos poetas la imagen sirve para poner de manifiesto el dominio en ellos del deseo y el apetito sexual. El primero ya ha superado esa fase de su vida merced a la intervención de Dios, mientras que el segundo aún sufre para superarla, seguramente porque aún no ha recibido la ayuda divina. Ésa es, quizá, la gran diferencia entre los dos autores.

\section{LOS DOS SONETOS «IN MORTE»}

Tras el cancionero amoroso, en las ediciones de Amoros, se incluyen las «obras de mort», en las que Ausiàs March lamenta la muerte de su segunda esposa para reflexionar sobre el tipo de amor que ha podido subsistir. En varias ocasiones reconoce que en tales circunstancias sólo el honesto, al que llama «amistança pura», es el que logra vencer la muerte. Esta forma de amor, a diferencia del mixto, no provoca ninguna clase de turbación ni dolor, y sólo se alcanza tras haber eliminado el mínimo residuo de materia. Boscán, por su 
parte, no ha tenido que escribir ningún poema in morte, porque su esposa le sobrevivió bastantes años, pero, en cambio, decide dedicar dos sonetos, el CXXVIII y CXXIX, a la muerte de su buen amigo Garcilaso. En el primero, compara al toledano con el héroe griego Aquiles por creerlos a los dos acreedores a una gloria que tanto les cost6 obtener en sus cortas vidas. Para establecer esa comparación alude al pasaje de la lliada en que el héroe griego, tras consentir que le arrebataran a la joven Briseida, símbolo de su gloria por ser un trofeo de guerra, se dirige a su madre Tetis para exponerle, con lágrimas en los ojos, su desdichada situación:

El hijo de Peleo, que celebrado

Tanto d'Homero fue con alta lira,

Con su madre su mal llora y suspira,

La suerte lamentando de su "stado.

Que sobre habelle corta vida dado,

Pase tan adelante la su ira,

Que doquier que'l revuelva, si se mira,

Se vea de trabajos rodeado.

Si la fortuna d'un tal hombre's gloria,

Con gloria quedarás tú, Garcilaso,

Pues, con la de él, tu gloria va medida.

Tu esfuerzo nunca fue flaco ni laso,

Tus trabajos hicieron larga historia

$\mathrm{Y}$ cúpote, tras esto, corta vida (235-236).

No sabemos si leyo el pasaje en cuestión de Homero en la versión original, o si utilizó alguna de las traducciones al latín que se editaron a finales del siglo $\mathrm{XV}$ y a principios del siguiente. Veamos primero la versión original de esos versos para después cotejarla con las traducciones más difundidas en la época:

$[\ldots]$

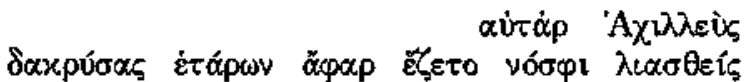

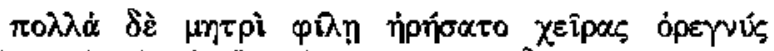

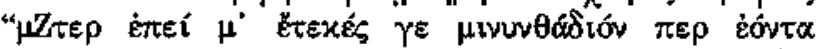

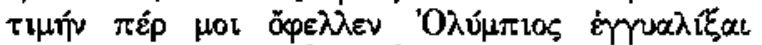

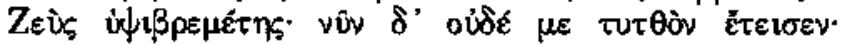

\section{[...]}

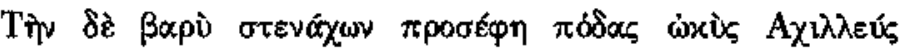

[...]

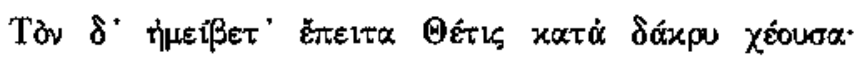

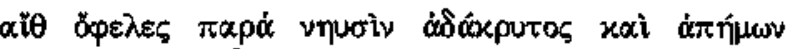

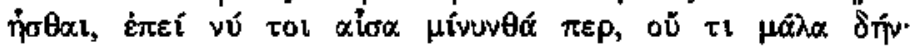




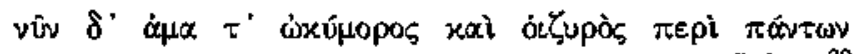

$$
\begin{aligned}
& \varepsilon \bar{\pi} \pi \lambda \varepsilon 0^{20}
\end{aligned}
$$

(Pero Aquiles, vertiendo en seguida abundantes lágrimas, se sentó, se apartó lejos de sus compañeros [...], y muchas veces a su madre amada imploró, extendiendo las manos: "Madre, ya que diste a luz a un ser de corta vida, honor debía darme el Olímpico, Zeus altitonante; por ahora apenas me ha honrado [...]" A ésta, suspirando fuertemente, habló Aquiles de pies ligeros [...] A éste replicó después Tetis, llorando: "Ojalá estuvieras al lado de las naves sin lágrimas ni penas, porque tu destino es ciertamente corto, no muy largo. Ahora al estar destinado a morir pronto unes el ser muy infeliz")

Las dos traducciones latinas más editadas desde 1470 son las de Lorenzo Valla y Nicolás Valle ${ }^{21}$. El primero optó por la prosa, mientras que el segundo por el verso, aunque prescindió de unos cuantos cantos o libros, entre ellos los tres iniciales. Si se sirvió de alguna de las dos, Boscán hubo de servirse por fuerza de la de Lorenzo Valla, quien, salvo alguna excepción, se ciñó bastante al texto griego:

At Achilles enumpentibus lachrymis, deflectens ab aspecto caeterorum solus [...] manusque tendens matrem saepius compellabat: "Mater, quae me hoc fato genuisti, ut iuveni, atque in ipso sit aetatis flore moriendum, spondebas tantum intra hoc breve tempus aevi Iovem mihi magnum decus esse tributurum, en nunc ne tantillum quidem tribuere voluit [...]". Cui Achilles alte ducens cum gemitu suspirium [...] inquit[...] Hac filii oratione Thetis audita tota in lachrymas resoluta: [...] "quod utinam hoc tibi parvulum aevi (nam non sera mors, sed vicina te manet) liceret sine lachrymis ac sine offensione consumere. Nunc autem vita es inter omnes principes quam brevissima tam acerbissima futurus" 22

("Pero Aquiles, habiendo estallado en lágrimas, apartándose de la mirada de los demás [...], tendiendo las manos, a menudo llamaba a su madre: 'Madre, que me engendraste con este destino, ya que he de morir joven y en la misma flor de la edad, me prometiste que sólo dentro de este breve tiempo de vida Júpiter me había de conceder una gran gloria, he aquí que ni un poquito ha querido darme [...]". A la que Aquiles, formando profundamente suspiros con gemidos, dijo [...] Habiendo oído este discurso de su hijo, Tetis, toda desatada en lágrimas [...] "que ojalá esta breve vida (pues la muerte no te será tardía sino próxima) te permita terminar sin lágrimas y sin desgracias. Ahora tú has de ser, entre todos los príncipes, de vida brevísima como muy cruel")

${ }^{20}$ Para el texto griego, hemos empleado la edición de José García Blanco y Luis M. Macía Aparicio, Ilfada, Madrid, Consejo Superior de Investigaciones Científicas, 1991, I, págs. 23 y 26.

${ }^{21}$ Para una lista de las ediciones de la Ilfada en latín, véase Philip $\mathrm{H}$. Young, The Printed Homer: A 3000 Year Publishing and Translation History of the Iliad and the Odyssey, McFarland \& co., Jefferson NC, 2003, págs. 176-182.

${ }^{22}$ Homero, llias, version latina por Lorenzo Valla, Lipsiae, 1512, fols. xii vo y xiii ro. 
Otras traducciones son las de Pier Candido Decembrio y de Andrea Divo, las dos en verso, aunque no difundidas por igual. De la del segundo se conservan varias ediciones venecianas $(1534,1537,1538,1540)$, mientras que la del primero no conozco ningún impreso antiguo. Decembrio es bastante fiel al original, pero en algún momento parece traducir con más libertad. Veamos cómo lo hace:

\author{
At Achilles \\ Lacrimans sine sociis concedit solus [...], \\ Multaque matri care, extensis manibus, inquit: \\ "Mater! Ex quo me haud longevum pepiristi, \\ honorem certem mihi debuit Olimpius tradere \\ lupiter altitonans, nunc me nec modicum curat \\ [...] \\ Hanc graviter suspirans, affatur citus Achilles \\ [...] \\ Huic autem retulit lacrimas fundens Thetis : \\ [...] \\ "Certe debuisti in navibus sine lacrimas illesusque \\ sedere, postquam fatum brevis evi neque diu iam! \\ Nunc autem cito periturus ingloriusque ultra omnes \\ es" 23
}

(Pero Aquiles, llorando, se retiró solo sin sus compañeros [...], y muchas veces, con las manos extendidas, dijo a su querida madre: "¡Madre! Desde que me engendraste no longevo, el Olímpico Júpiter altitonante debŕa darme honor; ahora no se preocupa apenas de mí [...] A ésta, suspirando gravemente, el animoso Aquiles hablo [...] A éste sin embargo Tetis contó derramando lágrimas [...] "En verdad te debiste sentar en las naves sin lágrimas y sin daño, después que el hado es breve, y no ya de mucho tiempo. Ahora sin embargo tu habrás de morir pronto y vivir sin gloria más que todos")

Andrea Divo, por su parte, ofrece una versión aún más literal, como anuncia desde el título, «ad verbum transtulit», en la que no se deja ningún elemento, por mínimo que pueda ser. Comprobémoslo:

\title{
Sed Achilles
}

Lachrymans seorsum a sociis statim sedit separatas

[...] multa autem matri dilectae precabatur manus porrigens:

${ }^{23} \mathrm{El}$ texto aparece reproducido por Guillermo Serés, La traducción parcial de la "lliada" del siglo XV. Estudios y textos complementarios, Tesis doctoral dirigida por Francisco Rico, Barcelona. Universidad Autónoma de Barcelona, 1987, vol. II, págs. 190-194. Para la versión castellana, quizá del hijo del marqués de Santillana, don Pero González, véase Guillermo Serés, $L a$ traducción en Italia y España durante el siglo XV. La "líada en romances y su contexto cultural, Salamanca, Universidad de Salamanca, 1997, págs. 115-116. 
"Mater, postquam me perperisti brevis temporis existentem Honorem mihi debetur Olympius tradere Iupiter altitonans, nunc autem neque me paulum honoravit [...] Hanc autem graviter suspirans, allocutus est pedes velox Achilles:

[...]

Huic respondit postea Thetis lachrymas effundens:

[...]

Utinam posses apud naves sine lachrymis et illesus

Sedere, quoniam tibi parca paulum neque multum diu!

Nunc autem simul cito moriturus et aerumnosus supra omnes $\mathrm{Es}^{24}$.

(Pero Aquiles, llorando aparte, se sentó separándose de sus amigos [...]; muchas veces rogaba a la madre querida alargando los brazos: "Madre, después que me pariste para vivir una corta vida, honor debía concederme el altitonante Júpiter; ahora, sin embargo, ni un poquito me ha honrado [...] A esta gravemente suspirando, Aquiles el de los pies veloces habló [...] A éste sin embargo respondió después Tetis, derramando lágrimas [...] "Ojalá puedas en las naves sentarte sin lágrimas y sin daño, porque a ti la parca te ha concedido poco tiempo, y no mucho. Ahora sin embargo to habrás de morir pronto al tiempo que eres desgraciado más que todos").

Al evocar a Aquiles, en el primer cuarteto de su soneto, Boscán lo presenta llorando y suspirando junto a su madre Tetis ("con su madre su mal llora y suspira"), siguiendo muy de cerca el texto de Homero, ya sea en su versión original, $\delta \alpha x_{p} \hat{v} \sigma \alpha \varsigma$, o en cualquiera de las traducciones latinas, "enumpentibus

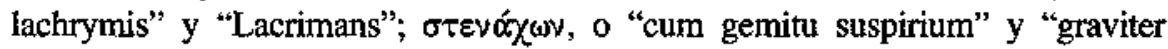
suspirans", etc. En el segundo terceto, se lo imagina destinado a sufrir dos grandes inconvenientes, la muerte prematura y la desdicha, "Que sobre habelle corta vida dado [...] se vea de trabajos ['sufrimientos'] rodeado", y en tan rápida caracterización coincide con la que brinda la madre al intentar consolarlo,

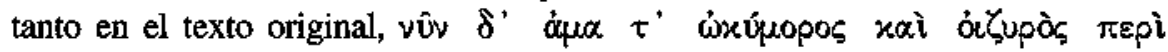
$\pi \alpha{ }^{\prime} \nu \tau \omega \nu / \tilde{\varepsilon} \pi \lambda{ }^{2}$, como en las diversas y diferentes traducciones, "Nunc autem vita es inter omnes principes quam brevissima tam acerbissima futurus", "Nunc autem cito periturus ingloriusque ultra omnes/ es", "Nunc autem cito periturus ingloriusque ultra omnes/ es", o "Nunc autem simul cito moriturus et aerumnosus supra omnes/ Es". Sin embargo, el poeta barcelonés ha optado por la construcción "rodeado de trabajos" para reproducir el adjetivo griego ó Ł̌upòs ("penoso, lamentable'), o los latinos "acerbissima", "inglorius" y "aenumnosus", y su sustantivo, "trabajos" ('sufrimientos'), es de un campo semántico muy afín a "aerumnosus" ('trabajoso, oprimido de fatigas o trabajos'), incluso más que a ò̀ $\zeta_{\text {upò }}$, pero que tiene poco que ver con "acerbísima" o "inglorius".

24 Véase Guillermo Serés, La traducción parcial..., vol. III, págs. 1221-1227. 
En el primer terceto, en que ya introduce la comparación con Garcilaso, Boscán duda de si el héroe griego es acreedor de una gloria que los propios dioses le negaron ("Si la fortuna d'un tal hombre's gloria"), y en semejante concesión parece haberse inspirado en reivindicaciones del propio personaje, concretadas en ö́ $\varphi$ e $\lambda \lambda e v$, 0 en los equivalentes latinos "magnum decus" o "honorem", sustantivos los tres cercanos a la palabra usada por nuestro poeta ("gloria"). Sin embargo, tampoco cabe descartar que Boscán, al atribuir a Aquiles una gloria en consonancia con su corta vida, se haya vuelto a fijar en el discurso de la madre en la versión de Decembrio, donde esas dos cosas se dan como incompatibles, "cito periturus ingloniusque". Sea como fuere, resulta curioso que la gloria que reclama Aquiles tenga que ver con la mujer, Briseida, que le mandó arrebatar Agamenón. Quizá el barcelonés pensara en una gloria afín para su amigo, a quien el Emperador no perdonó sus amores con Guiomar Carrillo: de hecho esa relación con la madre de Lorenzo Suárez de Figueroa parece ser el origen de todos los 'trabajos' del toledano.

En el soneto CXXIX, tras alabar al amigo, Boscán le reprocha no habérselo llevado con él al más allá, en vez de dejarlo en esta "mortal tierra"; al expresar tales sentimientos parece evocar el tipo de amor más puro, el honesto, que Aristóteles identificaba con la verdadera amistad y que el propio Garcilaso ya había invocado al comienzo de la epístola que le dedica. Al igual que le ocurre a March con la muerte de su segunda esposa, le sucede al barcelonés con la del poeta toledano: los dos aspiran a un amor o amistad en que han eliminado cualquier residuo corporal, el amor o la amistad más pura y sincera, que no había podido inspirarles ningún ser vivo.

\section{UNA CANCIÓN MORAL}

En las dos ediciones de Amorós, la poesía de March se cierra con un último apartado, en el que se incluyen poemas de tema moral, "obres morals" (así se llama la sección). En el postrer poema, el CV, el autor valenciano pide ayuda a Dios para poder acceder a él, pero se siente incapaz de conseguirlo porque no ha podido vencer los deseos carnales, y siente miedo, por ese motivo, al pensar en el posible destino de su alma. En cualquier caso, parece esperanzado al recordar que "de semblant mal guarí ella [la sangre de Dios] a molts altres" (v. 14).

Boscán clausura el libro II con una canción de tema parecido, en la que se presenta salvado gracias a la intervención divina ${ }^{25}$. Atribuye a Dios, al igual

${ }^{25}$ Para la simbología del número 153, que es el número de versos que tiene la canción de Boscán, véase Antonio Armisén, op. cit., págs. 409-410, y «Composición numérica e imitación. 
que hace March, la capacidad para curar toda clase de heridas, incluidas las provocadas por amor. A diferencia del poeta valenciano, no parece tener dudas sobre la misericordia del Señor:

$$
\begin{aligned}
& \text { Mas nuestro Dios, a quien tanto costamos, } \\
& \text { Que derramó su sangre por nosotros, } \\
& \text { Inventa en nuestros males grandes curas. } \\
& \text { Muchos dolientes sana, unos con otros [...] } \\
& \text { Pues Tú, Señor, olvidas } \\
& \text { Tu perjüicio de mi culpa clara, } \\
& \text { ¿cómo podrá ya ser que mis heridas } \\
& \text { con tu sangre no queden corregidas? (238-239). }
\end{aligned}
$$

También Bembo, poeta petrarquista donde los haya, decide terminar sus rime con una balada, si bien bastante más breve, de características muy similares: de hecho, la balada en cuestión sólo aparece en la tercera edición de las Rime, la póstuma de 1548, pero seguramente fue compuesta muchos años antes «per far da chiusa spirituale alla prima, non pubblicata, racolta delle rime, intomo al $1510 »$. En la balada, el futuro cardenal romano invoca a Dios desde el primer verso para pedirle piedad, recordando que Él murió en la cruz para redimir todos nuestros pecados:

Signor, quella pietà, che ti constringe Morendo far del nostro fallo ammenda [...]

Tu, Padre, ne mandaste

In questo mar, e tu ne scorgi a porto ${ }^{26}$

Bembo y Boscán, pues, deciden incluir como culminación de sus respectivos cancioneros un poema en el que reconocen su arrepentimiento por una vida entregada al amor. El italiano había concebido la tercera edición de sus Rime, ampliada y corregida con respecto a las dos anteriores, la de 1530 y 1535, como un cancionero petrarquista con dos partes muy nítidas: una primera en que canta especialmente a su compañera Morosina, con quien tuvo tres hijos, y una segunda dedicada a la muerte de diversas personas, empezando por la de su hermano Carlo.

La gran diferencia entre March y Boscán radica en que el valenciano espera alcanzar, gracias a Dios, un bien que se le ha resistido toda la vida, el amor de tipo espiritual, mientras que el barcelonés agradece al Señor haberle librado de un amor que cree enfermizo y torturador para proporcionarle otro

El 153 de la pesca milagrosa, la exégesis de Agustín y su huella en Petrarca y Boscán», Cuadernos de Filología italiana, 11, 2004, págs. 75-98.

${ }^{26}$ Pietro Bembo, Prose e rime, ed. Carlo Dionisotti, Turín, UTET, 1966, pág. 649. 
más sano, al que no le ha sido fácil adaptarse, pero al que ha acabado adaptándose. Los dos poetas, en cualquier caso, resuelven introducir tales reflexiones después de unos cuantos poemas in morte.

\section{CONCLUSIÓN}

Boscán empezó cultivando las trovas italianas sin saber si el conjunto de todas ellas tendría o no una unidad: compuso una serie de poemas en los que predominaba, al margen de su carácter disperso, un tratamiento bastante homogéneo del tema amoroso (esos sonetos y canciones son las que aparecen en el manuscrito $L$ ). Más adelante, seguramente para celebrar su boda en 1539 con doña Ana Girón de Rebolledo, escribió nuevos poemas en que cantaba un amor muy distinto al que había cantado en los que ya tenía escritos: para introducir la transición de una a otra parte, no marcada por ningún tipo de indicación tipográfica, redactó unos cuantos sonetos inspirados directamente en un poema de Ausiàs March, el que en algunas colecciones abre el cancionero. Por el principio, también decidió añadir nuevos sonetos, entre ellos cuatro proemiales, y el primero también con claras reminiscencias del poeta valenciano. Para semejante estructura, se basó, no tanto en el Canzionere de Petrarca, sino en las obras de March, en el orden y disposición con que el editor barcelonés Carles Amorós estaba preparándolas para sacarlas el mismo año que los textos de Boscán. Es, sin duda, difícil de demostrar hasta qué punto las ediciones de las obras de los dos poetas fueron paralelas, pero, por el enorme parecido en la estructura y en otros detalles de menor importancia, cabe suponer que para las dos se adoptaron criterios similares. Incluso me atrevería a sugerir que nuestro poeta pudo ser en parte responsable de la disposición que en la imprenta de Amorós se dio a los poemas del valenciano. 